\title{
Ser Professor Formador de Professores a Distância: perspectivas constitutivas
}

\author{
Being Teacher Teacher Trainer Distance: \\ constitutive perspectives
}

\section{Liliane Campos Machado*}

Universidade de Brasília, Brasília, DF, Brasil

\section{Resumo}

Este artigo resulta de pesquisa desenvolvida no estágio de pós doutoramento e tem como temática a formação dos professores formadores de professores, em cursos ofertados na modalidade de Educação a Distância. Objetivo investigar a percepção dos professores sobre a formação que receberam para formar professores por meio do ensino a distância. A nossa questão norteadora foi: Qual a percepção dos professores sobre a formação que receberam para formar professores por meio do ensino a distância? Que saberes, que currículos e que experiências eles possuem, estando na condição de formadores no curso de Pedagogia a distância da UAB/Unimontes? Adotamos uma metodologia quanti-qualitativa, a partir da análise de conteúdo. Os principais achados da pesquisa em relação ao professor que atua

LCM: Doutora em Educação, e-mail: Icmpedagogia@yahoo.com.br 
no curso de Pedagogia a distância da UAB/Unimontes foram: temos um professor na faixa etária entre quarenta e cinquenta. Os professores se formaram para atuar na EaD a maioria em cursos de extensão. Todos quando iniciaram o trabalho na UAB/Unimontes já tinham alguma experiência com a EaD embora muitos admitam que estão aprendendo muito ao desenvolver trabalho. Eles são otimistas com relação às novas tecnologias. Acreditamos que a qualificação do trabalho docente, na modalidade de $\mathrm{EaD}$, só ocorrerá se o profissional tiver consciência de que essa modalidade de ensino não é uma nova roupagem ao ensino presencial.

Palavras-chave: Formação docente. Educação a distância. Professores formadores de professores.

\begin{abstract}
This article results from research conducted at the stage of post-doctoral and has as its theme the training of teacher educators of teachers, courses offered in the form of distance education. We aimed to investigate the perceptions of teachers about the training they received to train teachers through distance education. Our guiding question was: What is the perception of teachers about the training they received to train teachers through distance education? That knowledge, that curricula and experiences that they have, being in the condition of trainers in pedagogy course distance of UAB / Unimontes? We adopt a quantitative-qualitative methodology, from the content analysis. The main findings of the research in relation to the teacher who acts in the course of Pedagogy distance of UAB / Unimontes were: we have a teacher between the ages of forty and fifty. Alumni teachers to work in EaD mostly in coursework. All work when initiated at UAB / Unimontes already had some experience with EaD although many admit they are learning to develop much work. They are optimistic about the new technologies. We believe that the classification of teachers' work in the form of EaD, will only occur if the trader has realized that this type of education is not a new guise to face teaching.
\end{abstract}

Keywords: Teacher Training. Distance education. Former teachers of teachers. 


\section{Introdução}

Este artigo resulta de uma pesquisa que se situa no contexto da formação dos professores formadores de professores. A escolha pela pesquisa no campo formação do formador de professores na Educação a distância, justifica-se, principalmente, porque ele contempla a formação, profissionalização, saberes e práticas docentes. Assim, percebemos a possibilidade de uma discussão sobre a formação de professores e as possíveis transformações socioculturais e pedagógicas na prática docente. O desejo pela investigação se deu durante a nossa atuação como professor formador, em cursos presenciais e a distância e, esse último, está se tornando uma realidade em nossa região, embora a discussão sobre EaD seja recente no contexto da Educação Pública Brasileira.

Escolhemos como espaço de investigação a cidade de Montes Claros, Minas Gerais Brasil, uma vez que toda a nossa formação e prática docente se deram nesse contexto. Nesse mesmo espaço surgiram também as inquietações e/ou indagações sobre a formação acadêmica e formação docente.

Para alguns questionamentos construídos ao longo de uma vida acadêmica, seja na condição de discente ou na de docente, conseguimos resposta com outras pesquisas, surgindo com essas outras tantas perguntas. São essas novas indagações que investigamos e pretendemos registrar neste trabalho.

As questões norteadoras são: Quem são os professores formadores? Como se formaram para atuarem na educação a distância (EaD)? Docentes: que saberes, que competências, que práticas? Como é percebida a formação e a profissionalização docente para atuar na formação por meio da EaD? Quais representações os formadores de professores fazem de suas tarefas de formador em EaD, de seu ofício, de sua profissão e de suas condições de exercício?

Durante o trabalho de pesquisa, envolvemos os professores com o objetivo de refletir sobre a formação dos formadores de professores e, como eles foram formados, que saberes e experiências possuem que hoje estão na condição de formadores no curso de Pedagogia da UAB/Unimontes. 
Pretendemos, com esse objetivo, responder a situação problema deste trabalho: Quem são os professores formadores de professores do curso de Pedagogia da Universidade Aberta do Brasil/Universidade Estadual de Montes Claros (UAB/Unimontes) e como se deu a formação desses professores para a sua atuação no curso de Pedagogia a distância da UAB/Unimontes.

Dentro dessa perspectiva, da Formação do Professor para a Educação a Distância apresenta-se, como uma possibilidade de resposta aos anseios, questionamentos e inquietudes intelectuais, oriundos da experiência de vida acadêmica e profissional. É vista também como uma forma de dar continuidade ao processo de formação, garantindo uma melhoria da qualidade social do ensino, e uma atitude pedagógica geradora de compromisso com a vida, em relação aos educadores/educandos, afeita às peculiaridades do contexto cultural e social da região onde se insere a pesquisa.

A seguir descrevemos o percurso metodológico dessa pesquisa.

\section{Percurso Metodológico}

Como percurso metodológico, adotamos o método de procedimento utilizado, em todo o trabalho: a pesquisa bibliográfica e análise de conteúdo.

Segundo Manzo (1971, p. 32), a bibliografia pertinente oferece meios para definir e resolver não somente problemas já conhecidos, como também explorar novas áreas onde os problemas não se cristalizaram suficientemente, pode ser também uma forma de examinar o tema sobre um novo enfoque, podendo chegar a conclusões inovadoras.

$\mathrm{O}$ enfoque trabalhado foi o quanti-qualitativo, entendendo-o como afirma Laville e Dione que as "perspectivas quantitativas e qualitativas não se opõem, e podem até parecer complementares, cada uma ajudando, à sua maneira, o pesquisador a cumprir sua tarefa, que é a de extrair as significações essenciais da mensagem" (LAVILLE e DIONNE, 1999, p. 225). 
Para a análise e interpretação dos dados coletados optamos pela análise de conteúdo categorial. Triviños (1987) e Bardin (1997) propõem três etapas básicas no trabalho com a análise de conteúdo: pré-análise, descrição analítica e interpretação inferencial. Nessa perspectiva, a análise de conteúdo presta-se tanto aos fins exploratórios, como aos fins de verificação, confirmando, ou não, proposições e evidências. A análise de conteúdo busca a essência de um ou mais textos, nos detalhes de suas informações, dados e evidências disponíveis. Assim, não trabalha apenas com o texto, mas também com o seu contexto (MARTINS e TEOPHILO, 2007).

Isto posto, apontamos então, o campo da investigação, que foi o curso de Licenciatura em Pedagogia, da UAB/Unimontes. A escolha pelo curso se deu pela nossa formação, que é nessa mesma área, também porque as discussões sobre a formação de professores são objetos de estudo da Pedagogia, que sempre foi o nosso foco de interesse e de pesquisa, e a EaD surgiu como uma nova modalidade de oferta do referido curso pela UNIMONTES.

Os sujeitos investigados foram cinco professoras formadoras, atuantes no curso de Licenciatura em Pedagogia, da UAB/UNIMONTES, uma Universidade pública do Estado de Minas Gerais (Brasil). Ainda que, no curso, existissem mais professores formados em licenciaturas diversas, optamos por conversar somente com os formadores que eram pedagogos e, por isso, somente cinco professores foram escolhidos, pois este curso da pesquisa.

O instrumento utilizado para a coleta de dados foi a entrevista que é utilizado nos vários campos das ciências humanas e sociais. Estes instrumentos têm o objetivo de obter informações do entrevistado sobre o assunto. Apesar de existirem vários tipos de entrevistas, trabalhamos com a "entrevista não estruturada" (LAKATOS, 1991, p. 80), dando ao entrevistado a liberdade de conduzir a resposta, trabalhando com perguntas abertas.

A entrevista foi aplicada depois de prévio agendamento com as professoras. Combinamos com elas que a entrevista seria gravada. Não houve objeção por parte de nenhum docente. No início de cada gravação, 
indagamos se poderíamos utilizar os nomes das professoras ou se preferiam que fossem usados codinomes. Decidimos adotar codinomes para que fosse mantido o anonimato das professoras entrevistadas, por isso, neste trabalho, eles serão identificados por letras do nosso alfabeto.

Ao término de cada entrevista, comprometemo-nos a transcrever toda a gravação e, em seguida, enviá-la ao docente para que ele pudesse avaliá-la e alterá-la, se necessário, permitindo que pudéssemos nos apropriar de seus discursos em nossas análises.

No decorrer da análise, respeitamos as três etapas propostas por Bardin (1997), fizemos, em primeiro lugar uma pré-análise do material coletado nas entrevistas, a partir de uma leitura de todo o material e da seleção de alguns temas que permitem evidências. Em seguida, fizemos a descrição analítica dos dados coletados e já pré-selecionados, codificamos e classificamos o material selecionado e, por último, fizemos a interpretação inferencial, o que nos possibilitou a construção de algumas bases para as considerações finais.

Toda a análise de conteúdo categorial foi desenvolvida a partir do roteiro de entrevista. Neste artigo apresentamos as discussões que fizemos sobre o assunto e não apresentamos o roteiro de entrevista e nem as tabelas criadas por categoria.

Investigar a formação de professores que formam outros professores, a partir da EaD, proporciona-nos reflexões importantes sobre diversos elementos que incidem sobre o desenvolvimento pessoal e profissional do professor, como saberes, identidade docente, a profissionalização dos formadores, as representações sobre os saberes e as práticas.

\section{A Educação Aberta e à Distância}

Vieira (2003), conceitua a Educação Aberta e a Distância como um processo pelo qual professores e estudantes buscam a informação, visando à construção do conhecimento, a partir das experiências e dos interesses de ambos, em espaços e tempos síncronos e assíncronos, por meio 
de um sistema de aprendizagem mediado por diferentes meios e formas de comunicação. Assim, na $\mathrm{EaD}$ a interatividade entre os atores envolvidos é indireta e mediatizada por uma combinação de meios tecnológicos e linguagens de comunicação.

Ao assumirmos essa conceituação, entendemos que ela tem origem na concepção dialética de educação. Para Dias (2004, p. 28), a "Educação aberta e a Distância apresenta-se como forma de educação, que possibilita a democratização do conhecimento independente do tempo e do espaço". Sendo assim, a EaD torna-se flexível, adaptando-se ao perfil do estudante, considerando as perspectivas e exigências.

Esta modalidade de educação possibilitou a flexibilidade de tempo e lugar e, também, um trabalho através das redes colaborativas de aprendizagem. Vieira (2003, p. 06). As redes de aprendizagens tornam-se, assim, um sistema aberto dinâmico e flexível, no qual os integrantes do grupo podem interagir para atingir um objetivo comum, a construção do conhecimento.

\section{Contexto Histórico e Caracterização da EaD na Unimontes}

Segundo o histórico apresentado no Caderno Didático: Introdução à Educação a Distância do 1. Período UAB/Unimontes (2009, p. 15), a primeira experiência com a Educação a Distância na Unimontes foi o Programa de Capacitação de Professores (PROCAP), realizado no período de julho de 1997 a janeiro de 2005. O PROCAP teve a finalidade de contribuir para a melhoria da qualidade do ensino nas séries iniciais do ensino fundamental, em todo o Estado de Minas Gerais, o que resultou de uma ação conjunta, efetivada com o Poder Público Estadual e Municipal, por intermédio das Secretarias de Educação e Instituições de Ensino Superior do Estado de Minas Gerais.

No período de 2000 a 2006, vivenciamos a segunda experiência realizada com o Projeto Unimontes Virtual, que teve como objetivo criar, na comunidade acadêmica da Universidade Estadual de Montes Claros, 
uma cultura dinâmica de aprendizado e colaboração em rede, permitindo a interação entre todos os envolvidos. Para atingir o objetivo proposto, a equipe de professores responsáveis pela coordenação desse projeto desenvolveu um ambiente de aprendizagem, denominado "Virtualmontes", para ofertar cursos de extensão virtuais.

A terceira experiência relevante aconteceu no período de 20022005 quando a Unimontes participou, com outras Universidades, do Projeto Veredas, promovido pela Secretaria de Estado da Educação de Minas Gerais - SEE/MG, com o intuito de capacitar os 1.299 professores das séries iniciais do ensino fundamental, da rede pública de MG que estavam em efetivo exercício, mas não possuíam habilitação em curso superior.

A Unimontes participou por ocasião do Edital Nov/2006/UAB, apresentando propostas para implantação de 10 (dez) cursos de graduação. Em abril de 2008, nove dos dez cursos foram selecionados: Artes Visuais, Ciências Biológicas, Ciências Sociais, Geografia, História, Letras/ Espanhol, Letras/Inglês, Letras/Português, Pedagogia nos seguintes pólos no Estado de Minas Gerais: Buritizeiro, Cristália, Francisco Sá, Pedra Azul, Urucuia, Itamarandiba, Janaúba, Mantena, São João da Ponte, Carlos Chagas, Pompéu, Almenara, Ipanema, Lagoa Santa.

A seguir abordaremos a formação do professor formador e a $\mathrm{EaD}$, espaço onde discutiremos o papel do professor a partir da nossa opção conceitual.

\section{A Formação do Professor para a EaD}

Segundo Teodoro (1992), os professores são profissionais que devem ter uma função (re)criadora sistemática, sendo esta a única forma de proceder quando se tem alunos e contextos de ensino com características diversificadas.

Diante disso, a formação dos professores se torna um alvo crítico das nossas preocupações; quanto mais plural precisa ser, maior se 
torna a responsabilidade da sua formação. Como diz Nóvoa (1995) "Os professores vivem tempos difíceis e paradoxais. Apesar das críticas e desconfianças em relação às suas competências profissionais exige-se-lhes quase tudo. Temos que ser capazes de pensar a nossa profissão" (p. 12).

Acreditamos que os professores produzem saberes específicos ao seu próprio trabalho e são capazes de deliberar sobre suas próprias práticas. Corroboram com essa ideia: Freire (1996), Morin (2002), Prett (2005), e outros, que constataram que esses profissionais, na prática do ensino a distância, também constroem seus saberes paralelamente ao seu crescimento e desenvolvimento atuais.

Segundo Pereira e Moraes (s/d), a educação como formadora do ser humano está além da perspectiva de capacitação de "recursos humanos”, por isso, ela deve contemplar não apenas soluções para atender as atuais necessidades materiais da população. Deverá também contribuir para a emancipação humana como um dos requisitos para o exercício da cidadania. E nessa mesma perspectiva as autoras concebem a educação a distância.

Como já mencionamos e fundamentando-nos em Pereira e Moraes (s/d) a EaD rompe com a relação espaço/tempo, que caracteriza a escola convencional, e concretiza-se por intermédio da comunicação mediada por meio da mídia. Diferente de uma situação de aprendizagem presencial, em que a mediação pedagógica é realizada pelo professor em contato direto com os alunos. Na modalidade a distância, a mídia torna-se uma necessidade absoluta para que se efetive a comunicação educacional.

[...] alternativas de formação que foram desenvolvidas em várias instituições públicas de ensino superior em diversos pontos do país. Algumas dessas iniciativas passaram a incorporar a educação a distância como forma de poder atingir, sobretudo, os professores em exercício nas escolas públicas que não possuíssem uma formação escolar condizente com as exigências para o exercício profissional da docência. Foram implementadas com base em princípios discutidos e consensuados por vários grupos, buscando não só diminuir as estatísticas de carências na formação dos docentes da educação básica, mas, sobretudo, 
buscando uma nova qualidade para essa formação. Essas iniciativas foram acompanhadas e geraram várias reflexões sobre os caminhos tomados (Gatti, 2000), permitindo avanços em concepções e práticas (GATTI, 2002, p. 143).

Segundo a autora, pensar as propostas de formação de professores na modalidade educação a distância de várias universidades e programas do governo federal não trouxeram condições para sair de discussões sobre "o que aconteceria se..." para o plano das reflexões sobre práticas concretas e seus desdobramentos. Com isso, a questão da qualidade desejável para essa modalidade formativa, postulada teoricamente, pode enriquecer-se do confronto com as práticas.

Educar e educar-se a distância requer condições muito diferentes da escolarização presencial. Os alunos em processos de educação a distância não contam com a presença cotidiana e continuada de professores, nem com o contato constante com seus colegas. Embora possam lidar com os temas de estudo disponibilizados em diferentes suportes, no tempo e local mais adequados para seus estudos, num ritmo mais pessoal, isso exige determinação, perseverança, novos hábitos de estudo, novas atitudes em face da aprendizagem, novas maneiras de lidar com suas dificuldades. Por outro lado, os educadores envolvidos com os processos de ensino a distância têm que redobrar seus cuidados com as linguagens, aprender a trabalhar com multimídia e equipamentos especiais, maximizar o uso dos momentos presenciais, desenvolver melhor sua interlocução via diferentes canais de comunicação, criando nova sensibilidade para perceber o desenvolvimento dos alunos com quem mantêm interatividade por diferentes meios e diferentes condições (GATTI, 2000, 143).

Existe uma carência de estudos sobre a utilização da educação a distância e essa carência é mais acentuada na formação dos docentes do ensino superior quando se trata, especificamente, da formação pedagógica que, nesse nível de ensino, é considerada de menor importância (BELLONI, 1998). 
Nestas condições, algumas características devem ser asseguradas nesse processo para garantir uma boa qualidade formativa e que os alunos têm direito de usufruir em seus processos educativos (GATTI, 2002). Nesse texto, tentaremos apenas sintetizar algumas das características e fatores que têm evidenciado e/ou propiciado um nível qualitativo para a formação de professores a distância.

\section{Análise e discussão dos resultados}

Analisamos os dados a partir de cinco categorias que estabelecemos, são elas: categoria 1. Perfil docente; categoria 2. Formação para atuar em cursos modalidade de EaD; categoria 3. Experiência profissional; categoria 4. Perspectivas; e categoria 5. Formar através das novas tecnologias.

Iniciamos a nossa análise apresentando o perfil do professor formador, veja o quadro a seguir:

Quadro 1 - Identificação dos professores entrevistados

\begin{tabular}{llllllll}
\hline Identificação & Curso & Sexo & Titulação & $\begin{array}{l}\text { Ano de } \\
\text { graduação }\end{array}$ & $\begin{array}{l}\text { Tempo de } \\
\text { serviço no } \\
\text { magistério }\end{array}$ & $\begin{array}{l}\text { Tempo de } \\
\text { serviço no } \\
\text { magistério } \\
\text { superior } \\
\text { superior } \\
\text { - UAB }\end{array}$ \\
\hline A & Pedagogia & Feminino & Mestre & 1900 & 15 anos & 1 ano \\
\hline B & Pedagogia & Feminino & Mestre & 1981 & 14 anos & 09 meses \\
\hline C & Pedagogia & Feminino & Especialista & 1994 & 04 anos & 02 meses \\
D & Pedagogia & Feminino & Doutor & 1984 & 09 anos & 02 anos \\
\hline E & Pedagogia & Feminino & Mestre & 1989 & 19 anos & 06 meses \\
\hline
\end{tabular}

Fonte: Elaborado pela autora, 2013. 
Analisando a categoria um, observamos que as cinco professoras, iniciantes na modalidade de educação distância, compõem uma faixa etária entre quarenta e cinquenta anos, todas do sexo feminino, graduadas em Pedagogia, nas décadas de 1980 e 1990. Apenas uma professora não tem formação stricto sensu. Com relação ao tempo de docência, no magistério superior, percebemos que estão entre quatro e 19 anos no ensino presencial.

Utilizando o esquema explicativo de Huberman (1992) ${ }^{1}$ sobre as fases da carreira docente, percebemos que a maioria das professoras já passaram da fase de entrada na carreira (1-3 anos), estando entre a fase de estabilização e consolidação de um repertório pedagógico (4-5 anos) e a diversificação/questionamento (7-25 anos).

Essas professoras apesar de já estarem em uma fase de estabilização e consolidação no Magistério Superior, vivem a fase de entrada na carreira quando se trata do ser professor na educação a distância.

Com relação à categoria dois, formação para atuar em cursos modalidade de a distância, percebemos, a partir dos relatos das professoras entrevistadas, que a formação para atuar em cursos na modalidade "a distância” se deu por cursos de curta duração (cursos de capacitação/aperfeiçoamento) apenas um deles buscou titulação e desenvolveu pesquisa na área de $\mathrm{EaD}$.

No que se refere aos saberes, e as práticas dos docentes, nos seus depoimentos, as professoras sinalizam para pontos comuns que são demandados aos formadores de cursos a distância, tais como: melhor preparação de docentes e discentes para o ensino a distância; disciplinas

1 Huberman (1992, p. 39), traça uma descrição de tendências, em seus estudos sobre o desenvolvimento da carreira docente, que nos permite identificar como se caracteriza "o ciclo de vida dos professores". De acordo com esse estudo, o professor passa por uma fase de "sobrevivência" e "descoberta", ao iniciar seu percurso profissional, que possibilita o confronto com o novo e a exploração de possibilidades de ação, avançando, gradativamente, para uma fase de "estabilização", em que começa a tomar uma maior consciência do seu papel e responsabilidade, enquanto educador. Este ciclo, como define Huberman (1992, p. 47), não se constitui em etapas fixas, mas sim num processo dinâmico e bem peculiar ao percurso pessoal de cada professor.

Rev. Diálogo Educ., Curitiba, v. 17, n. 51, p. 251-270, jan./mar. 2017 
de ambos (alunos e professores), acompanhamento e monitoramento do processo de ensino e aprendizagem em tempos e espaços distintos, dentre outros. Fica claro, nas narrativas da maioria das professoras, que elas estão se formando, ao mesmo tempo em que estão implantando a UAB/ Unimontes.

Podemos afirmar que alguns investigados encontram-se na fase de consolidação de um repertório pedagógico e de diversificação/questionamento. Inspiramo-nos em Gauthier (1998) quando sugere que pesquisas sobre o saber da ação pedagógica poderiam contribuir para o aperfeiçoamento da prática docente e formação de professores. Assim, além dos conhecimentos científicos (provenientes da pesquisa acadêmica), o saber nascido na prática deve, também, ser considerado, opondo-se às abordagens dos estudos que separavam a formação e a prática cotidiana.

Podemos dizer que o exercício da ação docente requer preparo e disponibilidade para o trabalho, e esse não se esgota nos cursos de formação, mas para o qual há uma contribuição específica enquanto formação teórica (em que a unidade teoria e prática é fundamental) para a práxis transformadora (SCHMIED-KOWARZIK, 1983, p. 133).

Na terceira categoria, discutimos a experiência do professor formador para atuar em cursos de $\mathrm{EaD}$, e percebemos que a maioria das professoras entrevistados percebem que a EaD não é uma novidade na universidade, pois todos já haviam vivenciado a experiência com a mesma, seja em programas governamentais ou em privados. Embora todos possuíssem essa experiência, observamos que eles afirmam estar aprendendo a fazer a EaD no contexto da graduação. Concordamos com Tardif quando ele diz que uma das características mais importantes da formação do profissional docente é a sua historicidade. Isso porque a formação dos professores implica em um conjunto de saberes que vão sendo incorporados ao longo da própria vida, saberes estes que decorrem da sua imersão num contexto societário das relações que vão se estabelecendo com pessoas e instituições várias. Na profissão, continuam a incorporar novos saberes que se vão agregando ao processo formativo de construção da identidade profissional. Tardif (2002, p. 71) afirma, 
A socialização é um processo de formação do indivíduo que se estende por toda a história de vida e comporta rupturas e continuidades [...] Em sociologia, não existe consenso em relação à natureza dos saberes adquiridos através da socialização. [...] A ideia de base é que esses saberes (esquemas, regras, hábitos, procedimentos, tipos, categorias, etc.) não são inatos, mas produzidos pela socialização, isto é, através do processo de imersão dos indivíduos nos diversos mundos socializados, [...] nos quais eles constroem, em interação com os outros, sua identidade pessoal e social.

Dizer que o saber dos professores é temporal, significa dizer que, ensinar supõe aprender a ensinar. Nessa perspectiva, muitos autores já evidenciaram a importância das experiências familiares e escolares anteriores à formação inicial. Antes mesmo de ensinar, os futuros professores vivem nas salas de aula e nas escolas - seu futuro ambiente de trabalho - aproximadamente 11 a 14 anos. Tal imersão é, necessariamente, formadora, pois leva os futuros professores a adquirirem crenças, representações e certezas sobre a prática profissional, bem como sobre o que é ser professor e ser aluno. Muitas pesquisas mostram que esse saber originário da experiência anterior é muito forte, persistindo através do tempo, sem que a experiência universitária consiga apagá-lo ou mesmo abalá-lo.

Refletindo sobre a quarta categoria, percebemos que as perspectivas das docentes são otimistas em relação à educação a distância, mesmo apontando alguns entraves. $\mathrm{O}$ que mais nos chamou a atenção foi a falta de formação para atuar na $\mathrm{EaD}$, mas mesmo sem a formação necessária e estando vivendo o processo formativo do ser professor a distância, em serviço, observamos que essas professoras apostam e acreditam na qualidade do curso de Pedagogia da UAB/Unimontes.

Frente ao exposto inferimos que é preciso pensar em projetos de formação de professores que lhes garantam condições de compreensão e atuação em diferentes fases do processo de organização dos cursos: da concepção e planejamento à sua viabilização e avaliação. Uma formação abrangente e orientada que envolva o conhecimento do processo pedagógico, a seleção e adequação da proposta de curso ou disciplina, as 
especificidades dos meios tecnológicos envolvidos, a gestão do processo educacional em rede; a produção de materiais comunicativos; a condução dos processos e estratégias para acolhimento e permanência dos alunos em estado de aprendizagem permanente; entre tantas outras necessidades que são específicas dos múltiplos tipos de ofertas de modalidades de cursos a distância (KENSKI, 2012).

A última categoria, formar através das novas tecnologias, nos fez refletir sobre a clareza que tem algumas professoras, com a professora $\mathrm{D}$, quando afirma que "trabalhar com a EaD e suas tecnologias é atender às estratégias neoliberais”, mas que, tendo consciência dessas estratégias, podemos fazer uma educação de qualidade na modalidade da educação a distância.

Outro tema que nos chamou atenção foi a colocação da Professora $C$ quando ela percebe as possibilidades das novas tecnologias, desde que não substituam o professor.

Concordamos com Moraes (1996) que a formação de professores a distância deve ser pensada para além da apropriação e utilização de tecnologias de informação e comunicação. Precisamos pensar a formação de sujeitos construtores de conhecimento e pensadores de sua prática pedagógica, num mundo em constates mudanças e avanços tecnológicos. Desse modo, o professor é percebido como sujeito, "como parte de uma grande teia, um ser autônomo, mas integrante de totalidades maiores, um fio particular numa teia onde todos estão conectados" (MORAES, 1996, p. 65).

A complexidade de organização dos cursos a distância exige a atuação em equipes. As competências necessárias a um professor em um curso a distância são tantas que não se pode pensar na sua atuação isolada. Não podemos deixar, no entanto, que a atuação multifacetada e segmentada de professores existente, em grandes projetos educacionais a distância, seja a marca que caracteriza a identidade docente como a de outro profissional. Ele se transforma segundo Belloni (2001) de um professor com identidade individual para uma identidade coletiva chamada "professor". 
Encerrando a nossa discussão, evidenciamos que as professoras formadoras estão se preparando para atuar em EaD, porém em vários momentos das narrativas, estabelecem comparações com a educação presencial, o que nos fez perceber que a maioria pensa a EaD a partir da sua realidade na educação presencial. Algumas dessas professoras ainda não construíram uma cultura do ser professor em curso na modalidade de Educação a Distância.

\section{Considerações finais}

Apesar das possibilidades emancipadoras e democratizantes das tecnologias, há sérios riscos a considerar em relação à apropriação desses meios tecnológicos para fins mercantis e propagandísticos, que ferem os princípios éticos veiculando a cursos massificados, de baixa qualidade, alienantes, impeditivos da formação profissional e cidadã (KENSKI, 2012).

Novos papéis para professores e alunos são desejados no momento social em que nos encontramos. Como modalidade educativa, a EaD objetiva o pleno desenvolvimento do educando, preparando-o para o exercício da cidadania e qualificando-o para o trabalho, como expressam as diretrizes da educação nacional.

A formação de professores via EaD pode ser feita com maior qualidade, desde que todos compreendam as necessidades de mudanças nas estruturas e na qualidade da educação. Considerar as mudanças, não apenas em relação à fluência no uso e o conhecimento da lógica que permeia as mais novas tecnologias digitais, mas, também, o significado que o acesso à informação e as possibilidades de interação e comunicação trazem para a prática pedagógica (BRASIL, 2007).

Concordamos com os Referenciais de Qualidade de EaD de Cursos de Graduação a Distância (2007) quando eles evidenciam que desenvolver cursos de formação de professores a distância, utilizando as mais novas possibilidades tecnológicas, com velhos conteúdos e práticas 
pedagógicas obsoletas, é um desserviço à educação e à sociedade. É reforçar, ainda mais, o fosso que separa a preocupação com o oferecimento de educação de qualidade - base para o crescimento e desenvolvimento do país em uma era em que se privilegia o conhecimento - e a realidade educacional brasileira, com todas as suas dificuldades, atrasos e imperfeições (BRASIL, 2007).

A educação a distância, nesse contexto, relaciona-se diretamente com o desenvolvimento de uma cultura tecnológica que promova a atuação dos profissionais em ambientes virtuais. Trata-se de estruturar equipes interdisciplinares constituídas por educadores, profissionais de design, programação e desenvolvimento de ambientes computacionais para $\mathrm{EaD}$, com competência na criação, gerenciamento e uso desses ambientes.

Segundo Almeida (1998), a revolução vivida em nossa época é marcada pela telemática, pela robótica e pelas autopistas da informação. $\mathrm{O}$ autor defende a ideia doo professor deixar de lado o fatalismo e assumir a atitude do diálogo como a "nova cultura", questionando-se, sempre, acerca dos objetivos com que utiliza a tecnologia na educação.

Para que esse diálogo se torne possível é necessário que o professor tenha as competências que lhe permitam utilizar, de forma eficaz, as novas tecnologias. Esse professor precisa adquirir confiança nos recursos tecnológicos, para que possa aplicá-los ao currículo do curso, quer seja presencial ou a distância.

Em relação às professoras entrevistadas, observamos que elas têm um saber construído sobre o ser formador de professores. Em relação a EaD, as docentes possuem uma percepção sobre as necessidades de se consolidar uma nova postura para se fazer professor nessa modalidade de ensino. Elas percebem que essa nova postura gere novos paradigmas sobre a formação e os saberes docentes. A partir das vivências experienciadas por essas professoras, acreditamos que elas passarão a conceber a $\mathrm{EaD}$, sem estarem, necessariamente, estabelecendo comparações com a educação ofertada na modalidade presencial. 
A pesquisadora ousou definir o "bom professor" como aquele que tem como eixo de suas ações os saberes, o aprendizado, a pesquisa, os fazeres e as experiências e que, desse modo, torna-se o elemento imprescindível à transformação do aluno. Por isso, a formação desse professor não pode ser uma lista de aquisições lineares, cuja soma equivale ao todo. É necessário compreender a formação docente como um conjunto de tarefas complexas, que exija saberes experimentais, valorizando atitudes e formas para a globalidade do ofício de ensinar, significando mais do que a soma de competências múltiplas construídas a partir de uma postura reflexiva. Assim, as professoras entrevistadas assumiram uma identidade de professor profissional reflexivo para a educação a distância, ou seja, "um bom professor".

\section{Referências}

BARDIN, L. Análise de conteúdo. Lisboa: Edições 70, 1997.

BELLONI, M. L. Educação a distância mais aprendizagem aberta. Caxambu: $21^{\text {a }}$ Reunião Anual da ANPEd, GT Educação e Comunicação, 1998.

BELLONI, M. L. O que é Mídia e Educação. Campinas: Autores Associados, 2001.

BRASIL. MEC. SEED. Referenciais de Qualidade de EaD de Cursos de Graduação a Distância. Brasília, 2007. Disponível em: http://portal.mec.gov.br/seed/ arquivos/pdf/legislacao/refead1.pdf. Acesso emoutubro/2007>. Acesso em: 10 out. 2009.

GATTI, B. A. Formação de professores e carreira: problemas e movimentos de renovação. 2. ed. Campinas: Autores Associados, 2000.

GATTI, B. A. Formação de Professores a Distância: Critérios de Qualidade (2002). Disponível em: <http://www.tvebrasil.com.br/SALTO/boletins2002/ead/eadtxt 1b.htm >. Acesso em: 10 de outubro de 2014. 
GATTI, B. A. Formação de Professores a Distância: Critérios de Qualidade. 2002. Disponível em: <http://portal.mec.gov.br/seed/arquivos/pdf/4sf.pdf〉. Acesso em: 10 out. 2014.

GAUTHIER, C. et al. Por uma teoria da Pedagogia: pesquisas contemporâneas sobre o Saber Docente. Ijuí: Unijuí, 1998.

HUBERMAN, M. O Ciclo de vida profissional dos professores. In: NÓVOA, A. (org.). Vidas de professores. 2. ed. Portugal: Porto Editora, 1992. p. 31-61.

KENSKI, V. M. USP/ SITE Educacional. Ead e Formação de Professores: entre o Discurso Legal e a Prática Institucional. Disponível em: <http://www.isecure. com.br/anpae/446.pdf>. Acesso em: 10 out. 2012.

LAKATOS, E. M. Fundamentos de metodologia científica. 3. ed, São Paulo: Atlas, 1991. p. 66-85.

LAVILLE, C. e DIONNE, J. A Construção do Saber: manual de metodologia da pesquisa em ciências humanas. Porto Alegre: Artmed e Belo Horizonte: UFMG, 1999.

MANZO, A. J. Manual para la preparación de monografías: una guía para presentear informes y tesis. Buenos Aires: Humanistas, 1971.

MARTINS, G. A.; TEOPHILO, C. R. Metodologia da investigação científica para ciências sociais aplicadas. Atlas: São Paulo, 2007.

NÓVOA, A. Os professores e a sua formação. Lisboa: Dom Quixote, 1995.

PEREIRA, E. W.; MORAES, R. A. A educação a distância e os desafios na formação de professores no Brasil: breves apontamentos, 2009. Disponível em: < http://www. apagina.pt/arquivo/Artigo.asp?ID=6543>. Acesso em: 31 ago. 2012.

SCHMIED-KOWARZIK, W. Pedagogia dialética: de Aristóteles a Paulo Freire. Trad. Wolfgang Leo Mar. São Paulo: Brasiliense, 1983. 
TARDIF, M. Saberes docentes e formação profissional. 2. ed. Petrópolis: Vozes, 2002. TEODORO, V. D. \& FREITAS, J. C. (orgs.) Educação e Computadores. 2 ed. Lisboa Portugual: GEP (Gabinete de Estudos e Planejamento) - EUROPAM, 1992.

TRIVIÑOS, A. Introdução à pesquisa em ciências sociais: a pesquisa qualitativa em educação. São Paulo: Atlas. 1987.

UNIVERSIDADE ESTADUAL DE MONTES CLAROS. Caderno didático I: $1^{\circ}$ período de Pedagogia. Montes Claros: Unimontes, 2009.

VIEIRA, F. M. S. Ciberespaço e educação: possibilidades e limites da interação dialógica nos cursos a distancia, 2003. 129 f. Dissertação (Mestrado em Educação) - Faculdade de Educação da Universidade de Brasília - UnB, Brasília, 2003.

Recebido: 12/11/2015

Received: 11/12/2016

Aprovado: 24/07/2016 Approved: 07/24/2016 